\title{
Effects of experiential-based videos in multi-disciplinary learning
}

\author{
Khalid Bin Abdul Jabbar, Alex Ong, Jeanette Choy, and Lisa Lim \\ Republic Polytechnic, Singapore
}

\begin{abstract}
This study examined the use of authentic experiential-based videos in self-explanation activities on 32 polytechnic students' learning and motivation, using a mixed method quasiexperimental design. The control group analysed a set of six pre-recorded videos of a subject performing the standing broad jump (SBJ). The experimental group captured videos of two subjects performing six variations of the SBJ. They then proceeded to analyse those videos as with the control group. All students then attempted a worksheet designed to elicit various levels of principled understanding of the topic on "projectile motion". In addition, data on students' motivation to learn and learning outcomes were measured by using three subscales of the Motivational Strategies for Learning Questionnaire (MSLQ) - task value, critical thinking, and self-efficacy — both before and after the intervention. Data were also collected through online pre- and post-tests, classroom observations as well as reflection journals. No significant differences between the experimental and control groups in terms of the post-intervention results were found $(p>0.05)$. However, the results suggested that use of experiential-based videos and video-based tools may in fact be more beneficial for students who are weaker in critical thinking and self-efficacy, to gain a better understanding of their learning.
\end{abstract}

\section{Introduction}

The advancement in information and communication technologies around the world is changing the way knowledge is being transferred, especially in the field of education. To facilitate these changes, various tools that could have the potential to effectively and efficiently engage students have been described in recent literature. But what are the key features of such tools? A number of recent studies in this area have highlighted the importance of engaging students in an experiential learning journey (Shyu, 2000; Chee \& Liu, 2004; Manolas \& Kehagias, 2005). Others have focussed on introducing challenging mathematical and scientific concepts to the students (Shyu, 2000; Chee \& Liu, 2004). In a number of studies, video as a tool to enhance learning experience have been mentioned (Zahn et al., 2005). There seems to be increasing evidence for incorporating videos in education to improve decision-making skills and increase motivation (Yoo, Park, \& Lee, 2010). Some authors have also reported that video and video-based training could help in the retention of skill-based procedures (Nousiainen, Brydges, Backstein, \& Dubrowski, 2008) and in increasing the ability among students to identify their own strengths and weakness in a skill-based task (Yoo, Son, Kim, \& Park, 2009; Yoo et al., 2010). This preliminary study is an attempt to understand the possible effects of video-based reflections on the motivational levels and depth of understanding of students within a multi-disciplinary learning environment.

Videos are important feedback tools for students/athletes as well as coaches in the sporting arena. Such feedback needs to be appropriate as well as timely to be effective in a particular situation (Parikh, McReelis, \& Hodges, 2001). The use of videos and video-based technologies is not new in the field of sports performance analysis (Hughes \& Bartlett, 2002). Farrow and Abernathy (2002) have also indicated the possibility of the use of these technologies in assisting in improving anticipatory skills in tennis. Interestingly, there have been various studies in the field of medicine and nursing that have employed video-based technologies as effective means of providing feedback and support to students in learning the finer aspects of communication (Yoo et al., 2009). Videoing themselves during an activity provides a stronger platform for students to conduct self-awareness and self-evaluation on those tasks that they had earlier performed. The use of self-awareness and self-evaluation in conjunction with the videos could help students recognize their strengths and weaknesses. It could also allow them to be more responsible at each stage of their work (Yoo et al., 2009).

More importantly, self-evaluation is a key component of self-regulated learning (Zimmerman, 1989; Zimmerman, Bonner, \& Kovach, 1996). However, complex problem solving skills demand that a student go beyond the use of self-regulated learning strategies. Various complementary strategies have been 
discussed by educational psychologists and researchers. Among them, Chi, Bassok, Lewis, Reimann, and Glaser (1989) highlighted that students benefitted from trying to fill the gaps in their own mental models by trying to explain to themselves those steps that were missing in a set of physics examples. Such a phenomenon was termed a self-explanation effect. This effect has been suggested to be useful in facilitating deep learning, (Williams \& Lombrozo, 2010) but there is a dearth of information about how it is interpreted in video-based learning environments.

Problem-related verbalizations produced by good problem solvers were termed self-explanations (Chi, Bassok, Lewis, Reimann, \& Glaser, 1989). Self-explanation can facilitate refining or completing the mental model that the learners construct to better understand the task at hand (Chi, 2000). It is especially useful for students at the intermediate stage of skill acquisition. This is because self-explanation could be useful to learners to build upon and construct new knowledge/information based on prior knowledge. De Bruin, Rikers, and Schmidt (2007) investigated to what extent novice chess learners benefitted from providing self-explanations. Their study showed that asking novice learners to self-explain their move predictions strengthened the development of principled understanding. It suggested that the participants had developed principled understanding that made it possible for them to apply the learned principles in novel situations and tasks (Gelman \& Greeno, 1989). One has reached principled understanding when he/she has "acquired a correct mental model of a problem solving procedure" (Gelman \& Greeno, 1989). Thus, it is crucial that a learner of any domain, especially a scientific one, attains a complete understanding of the central principles of that domain in order to master it. As such developing principled understanding is important in many fields of scientific knowledge acquisition. Students who are aware of their better understanding of key concepts in a field are more likely to be better motivated (Ryan \& Deci, 2009). Thus, the level of motivation of a student could also be an indication of his/her understanding of the concepts.

Additionally, the provision of an authentic environment anchored in a meaningful and realistic context is beneficial (Gulikers, Bastiaens, \& Martens, 2005). An authentic learning environment provides a context that reflects the way knowledge and skills will be used in real life. This includes a physical or virtual environment that resembles the real world with real world complexity and limitations, and provides options and possibilities that are also present in real life (Herrington \& Oliver, 2000). However, in the context of learning a multi-disciplinary subject such as sports biomechanics, very few studies have been carried out with the focus on authentic learning environments.

The purpose of the current study was to investigate the effect of authentic experiential based videos in self-explanation activities and whether such a setup has an effect in helping the students develop principled understanding on the concepts of projectile motion. In this project, students from a local polytechnic, who were majoring in the field of Sports and Exercise Sciences, were introduced to the concept of projectile motion. Software that tracks the motion of an object in a video sequence was used as a tool to facilitate the learning process. The research also investigated whether such activities contribute to the overall motivational levels of the students. To our knowledge there have been very few studies that have looked at such an approach, especially in a multi-disciplinary field such as sports biomechanics. An understanding of the effects of videoing oneself in an authentic experiential context could provide the academic community with important information that could help in designing and planning other similar subjects or fields of studies.

\section{Method}

This study used a mixed method quasi-experimental design, incorporating both quantitative and qualitative techniques. Quantitative analyses were employed to investigate the hypothesized relationships between the teaching methods and student performance. They are discussed with reference to the scores of science tests (the pre-tests and post-tests) to investigate any significant difference in the abilities of the students to achieve higher results. Qualitative data included a combination of documentary interpretation (Erickson, 1986) and qualitative analysis (Strauss, 1987) of the facilitator's observational field notes of the students' verbal and physical cues that are indicative of motivation during the class. 


\section{Participants}

Thirty-two final year polytechnic students (16 males, 16 females) majoring in Sports and Exercise Sciences participated in this study. The students were from two intact classes, in which the students were randomly allocated by the Polytechnic, and each class was divided into four groups of students. One class was randomly assigned as the control group $(n=17)$ and another as the experimental group $(n=15)$. A single facilitator and similar instruction methods were used for both the groups. All participants were briefed and informed consent was obtained prior to the experiment.

\section{Instrumentation}

The data collected consisted of: (a) a self-report questionnaire adapted from the Motivational Strategies for Learning Questionnaire (MSLQ) (Pintrich, Smith, García, \& McKeachie, 1991, 1993; Duncan \& McKeachie, 2005); (b) online pre- and post-tests in the form of a quiz to test their problem solving skills; (c) students' reflection journals and (d) teacher's field notes, used in similar nature for other studies (Tan \& Saw Lan, 2011; Lai \& White, 2012), in which key observations of the students' verbal and physical cues that indicate on motivation were documented by the facilitators throughout the overall process of this session.

The students' motivational level and their learning strategies were measured using a self-report questionnaire adapted from the MSLQ. The adapted instrument consisted of 19 items that focussed on task value, self-efficacy for learning and performance and critical thinking. A 7-point Likert scale was used. The online pre- and post-tests were designed to objectively measure the level of conceptual knowledge of the students. They consist of five multiple choice questions (MCQs) that test various aspects of the concept on projectile motion in general. The order of presentation of the answers and questions as well as the numerical values within the questions, were manipulated between the pre- and post-tests. Worksheets were solely used to elicit various level of principled understanding of the students in the areas of SBJ and projectile motion. The worksheet questions were open-ended and required deeper understanding of the topic. They required the students to think critically and apply their understanding to novel situations. In addition, the investigators employed reflection journals to elicit the level of reflective thinking among the participants. Reflection journals promote reflective thinking and help integrate learnt theories with actual practical problems (Wong, Kember, Chung, \& Yan, 1995). The reflection questions were designed to assess the level of principled understanding through reflection achieved by the students at the end of the intervention.

\section{Procedure}

The intervention was conducted during the fourth week of a Sports Biomechanics module which employed problem-based learning as the main pedagogy. The first three problems had introduced the students to the basics of kinematics including linear and angular motion. At the end of the third problem, students from two classes were selected to complete an online pre-test on the next problem, projectile motion. One of these classes was assigned as the control group and the other as the experimental group. The fourth problem started in a laboratory setting. All students in the class were informed that they would be involved in a research project and written consent was obtained. The students were briefed that the primary objective of this project was to investigate how students engage in cross-disciplinary learning such as biomechanics using augmented reality based software aids. They were then instructed to complete the pre-test questionnaires (MSLQ).

The students were next provided with worksheets which contained instructions for the laboratory activities for the problem. The control group were provided with 3 laptops with augmented software preinstalled and with six pre-recorded videos of a subject performing a variety of SBJs (see Figure 1). Working in their groups, the students analysed various kinematic aspects of the jumps, such as the maximum and minimum vertical displacement and release velocity and direction. They used this information and other theoretical information to complete the worksheet. The experimental group were not provided with the six pre-recorded videos. Instead, they were instructed to record their own jumps based on the instructions provided. However, due to time constraints, only two students from each team attempted the SBJs, which were recorded by their team-mates. Thereafter, the whole team attempted the worksheet as a group with the aid of 3 laptops with the same pre-installed augmented software as the 
control group. At the end of the problem, the post-test questionnaires (MSLQ) were distributed to the students, who were provided the rest of the day to complete an online post-test and the reflection journals.

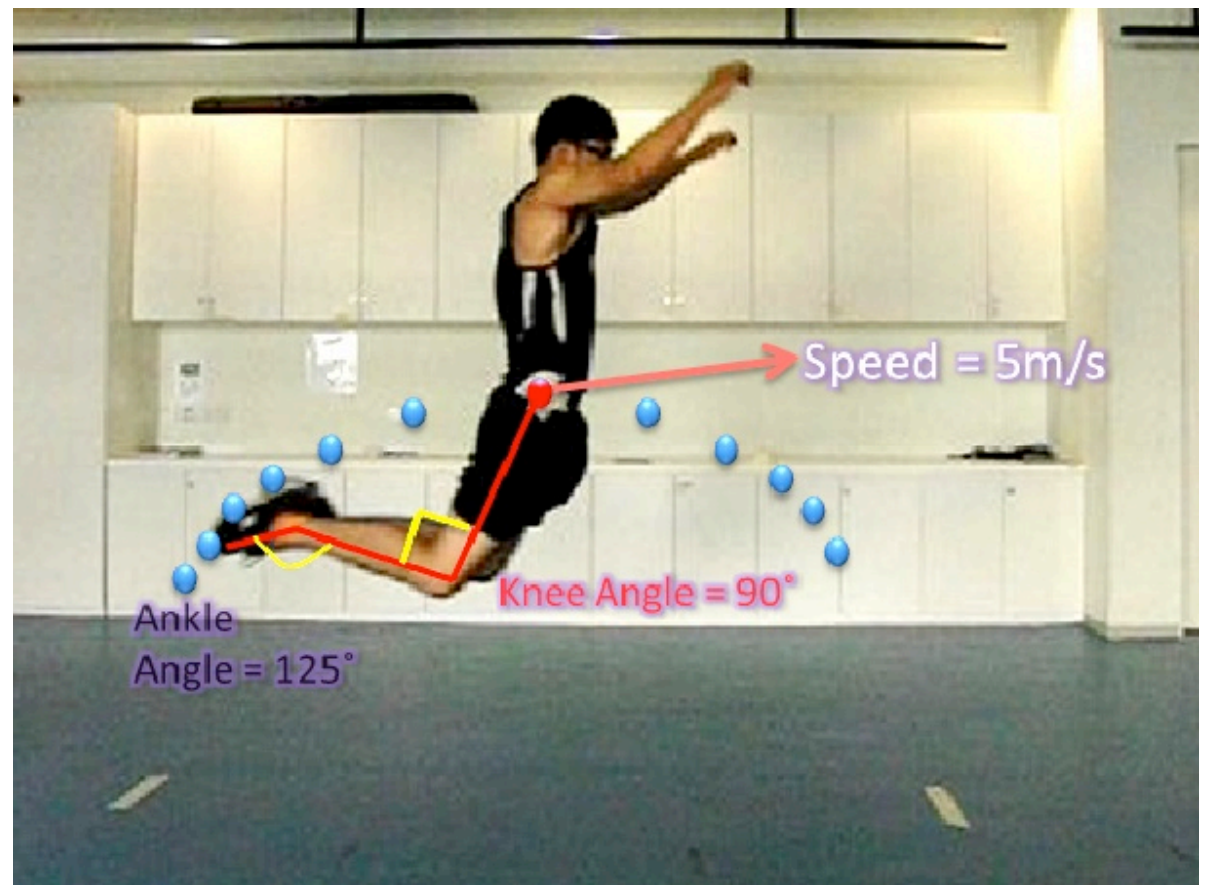

Figure 1. Video showing a subject performing the SBJ.

\section{Analysis}

There were two main objectives in this research. Firstly, to understand whether the use of authentic experiential based videos affected the students' performance in self-explanation tasks with reference to their ability to develop principled understanding of the key concepts introduced through the tasks. Qualitative inputs from the analysis of the reflection journals as well as those from the facilitator's field observational notes and quantitative inputs from the online pre- and post-tests were used to understand the extent of reflective thinking involved in achieving principled understanding. Secondly, to investigate whether such tasks affected the motivational levels of the students to achieve principled understanding of those key concepts, through the use of the triangulation method (Olsen, 2004). This triangulation method has been found useful in studies in confirming the qualitative data through the additional use of the quantitative data (Shih, 1998) and provides valuable completeness in various action research approaches (Hussein, 2009). Similarly, the quantitative inputs from the MSLQ as well as notes from the facilitator's field observations were used to understand to what extent motivation affected the students in achieving or trying to achieve principled understanding of the key concepts introduced during the class session.

To analyse the results from MSLQ, a 2 × 2 × 3 factorial design experimental setup with three independent variables: Time (pre and post), type (control and experimental) and scale (critical thinking, self-efficacy and task value) was employed. The dependent variable was the individual response for each question from the participants. For the online tests, a $2 \times 2$ factorial design experimental setup with two independent variables: Time (pre and post), type (control and experimental) was used. The dependent variable was the individual score for each question from the participants. The responses from the reflection journals were analysed by two independent raters using content analysis. Content analysis applies a systematic classification procedure to code identified themes or pattern from a content of text data (Downe-Wamboldt, 1992).

The qualitative framework analysis for both research questions involved a similar procedure. The investigators developed a coding system by searching through the data for regularities and patterns, and then wrote down words or phrases that represented those regularities and patterns. The process of analysing the qualitative data consisted of the following three steps: 
- coding and developing temporary coding categories;

- adopting the constant comparative process;

- defining categories and producing assertions.

First, these words and phrases formed temporary coding categories (Bogdan \& Biklen, 1992). Thereafter, the constant comparative method (Strauss, 1987) was used to decide the categories. Each time the new data were collected, it was constantly compared with the already existing data. Eventually, all data gathered were defined and organized into semantically related categories.

\section{Results and discussion}

This section reports the effect of introducing authentic experiential-based videos in a problem-based selfexplanation activity using various objective and subjective tools such as the MSLQ, online pre- and posttests, worksheets as well as reflection journals. The results are divided into two sections. In the first section, they report the extent of reflective thinking in relation to principled understanding. Thereafter, in the second section, the extent of motivation in relation to principled understanding are described and discussed.

\section{The extent of reflective thinking in principled understanding}

A total of 29 reflection journal responses were collected, of which 15 were from the control group, and 14 were from the experimental group. Using the coding scheme provided by Kember, McKay, Sinclair, and Wong (2006), two raters independently coded the level of reflection shown by the participants. The scheme (see Table 1) measures the level of reflective thinking in a holistic sense, based on the ideas of Mezirow (1997). According to the coding scheme, intermediate categories were permitted. Hence, if raters felt that the response was between two categories, this could be indicated with a "+" sign next to it e.g., if the response lies somewhere between understanding and reflection, this was coded as $C+$. After the initial independent coding, the two raters met together to negotiate differences. The final agreed ratings were then recoded on a numerical scale so that the ratings between the two groups could be analysed. The numeric ratings for the categories were: $A=7, B+=6, B=5, C+=4, C=3, D+=2, D=$ 1. The mean score for the experimental group was $4.21(S D=1.48)$ while that for the control group was $3.80(S D=1.37)$. Independent samples $t$-test found no significant difference between the two groups on their level of reflection demonstrating principled understanding. The Cohen's effect size measured was small (Cohen's $d<0.3$ ).

The reflection journal analysis indicated a trend to a higher level of reflection in the experimental group though the results were not significant. Additionally, there was a trend towards a positive improvement in the experimental group and a regression of results for the control, though the results were not significant and the effect size was small (Cohen's $d<0.3$ ).

As for the observations from the facilitator's field notes, the experimental group elicited the following:

The students were asking more questions and remained in class longer during break periods to complete and understand the tasks in the worksheet.

When asked to go for their breaks, they preferred to remain behind...very atypical of them...instead, they coordinated and asked their other classmates to buy back some snacks for them...

They were exploring "some new concepts" and were discussing amongst themselves; very chirpy and restless...constructive noise? (Teachers' field notes)

For the control group:

The students found it quite refreshing to play with the given videos and some commented that "it beats staying in class learning the chim (difficult) formulae etc..." 
The class behaviour was quite normal though they seemed a bit captivated with the interactive media.... guess it is Gen Y of sorts... (Teachers' field notes)

Finally, Figure 2 summarises the descriptive statistics for the online pre- and post-tests. It showed that only the experimental group improved in their online tests performance though the effect size was small (Cohen's $d=0.28$ ) and there was no significant difference between the two groups.

Most of the above observations are in agreement with observations noted by Shyu (2008), who was not able to find any significant differences in the problem-solving ability of students after the video intervention. This could be attributed to the fact that the intervention was not long enough to elicit any cognitive changes in the students. Perhaps, a longer intervention of 8 to 10 weeks or a full term might have shown significant differences in the cognitive and problem-solving abilities of the students (Braund \& Reiss, 2006).

\section{The extent of motivation for principled understanding}

Table 2 summarizes the descriptive statistics for the MSLQ. A two-way mixed ANOVA was employed to analyse the results from the questionnaire. The results revealed no significant differences between the change in responses for the control and experimental group over time for the self-efficacy for learning and performance scale (Wilks' Lambda $=0.951, F=(1,29)=1.485, p=0.233, \eta_{\mathrm{p}}{ }^{2}=0.049$ ). No significant differences between the change in responses for the two groups over time for the critical thinking scale (Wilks' Lambda $=0.982, F=(1,29)=0.536, p=0.47, \eta_{\mathrm{p}}{ }^{2}=0.018$ ). Similarly, there were no significant differences between the change in responses for the two groups over time for the task value scale (Wilks' Lambda $\left.=0.968, F=(1,29)=0.952, p=0.337, \eta_{\mathrm{p}}{ }^{2}=0.032\right)$. Thus, the findings suggest that there were no significant interaction effects for each of the three scales. No main effect of time for each of the three scales was established.

Next, the between-subjects effect for each of the three scales was investigated. Significant differences between the responses for the control and experimental group for the self-efficacy for learning and performance scale $\left(F=(1,29)=5.839, p=0.022, \eta_{\mathrm{p}}{ }^{2}=0.168\right)$ were observed. The results also highlighted significant differences between the responses for the two groups for the critical thinking scale $\left(F=(1,29)=5.118, p=0.031, \eta_{\mathrm{p}}{ }^{2}=0.150\right)$. However, no significant differences between the responses for the control and experimental group for the task value scale $\left(F=(1,29)=3.705, p=0.064, \eta_{\mathrm{p}}{ }^{2}=\right.$ 0.113 ) was established.

The following was observed during the classroom session and noted in the teachers' field notes by the facilitator. For the control group, some discomfort was observed:

Some students commented that the questions look weird ...they shared that the formula used seemed "a bit different" and "inappropriate" for the questions...

There was a table (of students) that mentioned that they were able to do it the last time round (pre-test); Like the last time round, it was like in secondary school...same pattern...but seems not to work this week? "Strange," they commented. (Teachers' field notes)

The experiment group seemed more focused and hardworking:

They mentioned that the questions were challenging but "felt" that they can still use the projectile formula...

Just like what they did (during the pre-test) and using again the formulae given...it should do the trick. They seemed more systematic and hardworking... consulting each other. They were forming "images" in their minds as they attempted to solve the questions...

They commented (with reference) to some movements such as... it was elongated like in the actual jump, you will extend or increase your moment of inertia; similar to like when the skater opens up her arms... (Teachers' field notes) 
Table 1

Summary of the four categories of reflective thinking (reproduced with permission by Kember et al. (2006))

\begin{tabular}{|c|c|c|}
\hline Level of reflection & Coding & Description \\
\hline Non-reflection & $\mathrm{D}$ & $\begin{array}{l}\text { - The answer shows no evidence of the student attempting to } \\
\text { reach an understanding of the concept or theory which } \\
\text { underpins the topic. } \\
\text { Material has been placed into an essay without the student } \\
\text { thinking seriously about it, trying to interpret the material, or } \\
\text { forming a view. } \\
\text { Largely reproduction, with or without adaptation, of the work } \\
\text { of others. }\end{array}$ \\
\hline Understanding & $\mathrm{C}$ & $\begin{array}{l}\text { - } \quad \text { Evidence of understanding of a concept or topic. } \\
\text { - } \quad \text { Raterial is confined to theory. } \\
\text { notes. } \\
\text { - Theory is not related to personal experiences, real-life } \\
\text { applications or practical situations. }\end{array}$ \\
\hline Reflection & B & $\begin{array}{l}\text { - Theory is applied to practical situations } \\
\text { - Situations encountered in practice will be considered and } \\
\text { successfully discussed in relationship to what has been } \\
\text { taught. There will be personal insights which go beyond } \\
\text { book theory. }\end{array}$ \\
\hline Critical Reflection & A & $\begin{array}{l}\text { Evidence of a change in perspective over a fundamental } \\
\text { belief of the understanding of a key concept or } \\
\text { phenomenon. } \\
\text { - Critical reflection is unlikely to occur frequently. }\end{array}$ \\
\hline
\end{tabular}

Table 2

Descriptive statistics for MSLQ

\begin{tabular}{lll}
\hline Variable & $\begin{array}{l}\text { Control } \\
(n=17) \\
\text { Mean }(S D)\end{array}$ & $\begin{array}{l}\text { Treatment } \\
(n=15) \\
\text { Mean }(S D)\end{array}$ \\
\hline Self-efficacy & $\underline{\text { Pre-test }}$ & \\
Critical thinking & $4.85(0.25)$ & $5.60(0.14)$ \\
Task value & $4.96(0.29)$ & $5.55(0.14)$ \\
Self-efficacy & $5.15(0.59)$ & $5.76(0.16)$ \\
Critical thinking & Post-test & \\
Task value & $4.93(0.25)$ & $5.54(0.13)$ \\
\hline
\end{tabular}




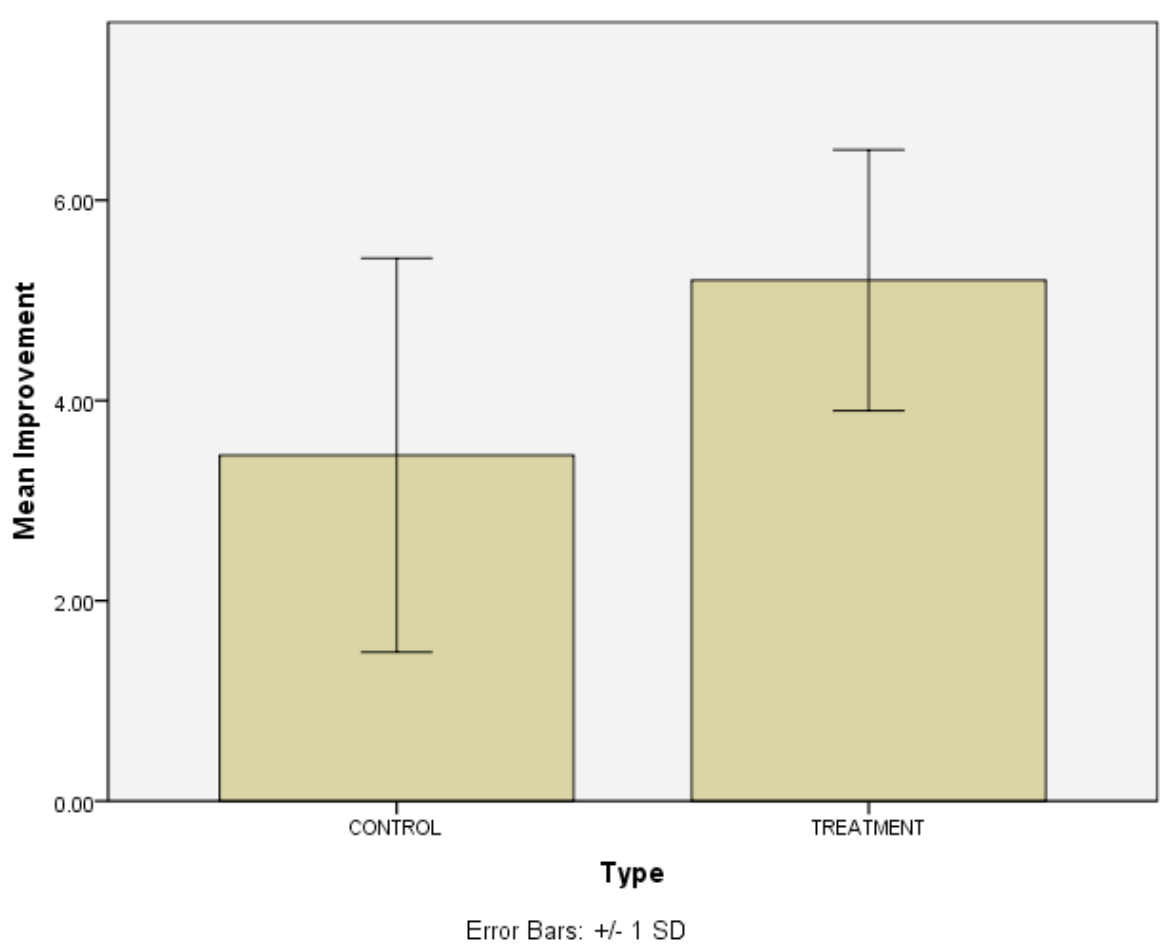

Figure 2. Improvement for online pre/post-tests.

This study, arguably, employed a positive control approach in its experimental design. This was done for ethical reasons, in that both groups should benefit from the study. Both groups were engaged in new experiences through the use of videos to analyse and to evaluate a physical activity, the SBJ. The use of video has been acknowledged as a positive pedagogical tool in collaborative learning (Shyu, 2000). This novel activity by itself seemed to have had an effect on the control group. Previous studies have highlighted that the use of video and video-based tools could have a positive effect in the problem-solving skills of the students by creating an environment that encourages a different type of learning (Shyu, 2000; Yoo et al., 2010). This was in conformity with the current study's observations, where the overall response for critical thinking increased for both the control and treatment group over time. However, a greater positive change in the control group was observed for all three subscales compared to the treatment group. In fact, the change was negative for the subscale task value and self-efficacy for the experimental group. On further analysis, the study found that there were pre-existing differences between the two groups in self-efficacy and critical thinking which indicated that the control group was actually an academically weaker group than the experimental group, in terms of these two scales. Lee, Shen, \& Tsai (2008) reported that the learning through e-learning in the context of a self-regulated learning strategy had positive effects on students who were less academically motivated. Similarly, it could be plausible that in the current study's context, the use of videos as a different method of learning could have been more appealing to the less academically inclined students. However, more studies are warranted to further confirm this speculation.

These pre-existing differences among the groups were unavoidable as the investigators had no control over the type of students assigned to either the experimental or control group and the assignment was randomly done at the start of the academic semester. However, the results showed that although the two groups were significantly different in self-efficacy and critical thinking before the start of the intervention, these differences were no longer significant after the intervention. This suggests that the intervention could have helped bring the weaker performing group closer to the stronger performing group in terms of these skills. This observation was similar to that of Nurizan (2009) who reported that less academically inclined students "benefitted and enjoyed" more through the use of cooperative learning strategies during their science lessons. Again, it could be plausible that in the current study, the less academically inclined students could have been more easily motivated by the change in the methodology and pedagogy of the lessons delivered. 


\section{Conclusion}

This study set out to investigate the effects of authentic experiential-based videos on students' learning and motivation. Although no significant differences were found between the control and experimental groups in terms of their post-intervention results, the investigation arguably suggests that such videos and video-based tools may potentially be meaningful and beneficial for students who are weaker in critical thinking and self-efficacy, to gain a better understanding of their learning. Additionally, video-based learning can potentially evoke more motivations in learning and given more time, deeper reflection through authentic activities may potentially positively contribute to more meaningful learning (Braund \& Reiss, 2006).

The current study only investigated the effects of video-based reflections on the motivational levels and understanding of students over a single day. Thus, the interpretation of the results may be extended more meaningfully and authentically into actual longer-duration classroom situations by addressing the following issues in future studies:

- the duration of intervention should be at the least a full term;

- only academically weaker students should be identified for such studies; and

- data should be collected periodically to identify possible trends rather than just at the end of the study.

Thus, future studies should aim to investigate how academically weaker students engage such instructional methods over a longer period.

\section{References}

Bogdan, R., \& Biklen, S. (1992). Qualitative research for education: An introduction to theory and methods. Boston: Allyn \& Bacon.

Braund, M., \& Reiss, M. (2006). Towards a more authentic science curriculum: The contribution of outof-school learning. International Journal of Science Education, 28(12), 1373-1388.

Chee, Y. S., \& Liu, Y. (2004). Grounding concept in percept: Learning physics experientially in multiuser virtual worlds. Proceedings of the 4t h IEEE International Conference on Advanced Learning Technologies (ICALT 2004), Joensuu, Finland, 340-344.

Chi, M. T. H. (2000). Self-explaining expository texts: The dual processes of generating inferences and repairing mental models. In R. Glaser (Ed.). Advances in instructional psychology: Educational design and cognitive science (Vol. 5, pp. 161-238). Mahwah, NJ: Lawrence Erlbaum Associates, Inc.

Chi, M. T. H., Bassok, M., Lewis, M. W., Reimann, P., \& Glaser, R. (1989). Self-explanations: how students study and use examples in learning to solve problems. Cognitive Science, 13, 145-182.

de Bruin, A. B. H., Rikers, M. J. P., \& Schmidt, H. G. (2007). The effect of self-explanation and prediction on the development of principled understanding of chess in novices. Contemporary Educational Psychology, 32(2), 188-205.

Downe-Wamboldt, B. (1992). Content analysis: Method, applications, and issues. Health Care for Women International, 13, 313-321.

Duncan, T. G., \& McKeachie, W. J. (2005). The making of the motivated strategies for learning questionnaire. Educational Psychologist, 40, 117-128.

Erickson, F. (1986). Qualitative methods in research on teaching. Handbooks of research on teaching. In M. C. Wittrock (Ed.), Handbook of research on teaching (3rd ed., pp. 119-161). New York: Macmillan. 
Farrow, D., \& Abernathy, B. (2002). Can anticipatory skills be learned through implicit video-based perceptual training? Journal of Sports Sciences, 20, 471-485.

Gelman, R., \& Greeno, J. G. (1989). On the nature of competence: Principles for understanding in a domain. In L. B. Resnick (Ed.). Knowing, learning, and instruction: Essays in honor of Robert Glaser (pp. 125-186). Hillsdale, NJ: Lawrence Erlbaum Associates.

Gulikers, J. T. M., Bastiaens, Th. J., \& Martens, R. (2005). The surplus value of an authentic learning environment. Computers in Human Behavior, 21, 509-521.

Herrington, J., \& Oliver, R. (2000). An instructional framework for authentic learning environments. Educational Technology Research and Development, 48(3), 23-48.

Hughes, M., \& Bartlett, R. (2002). The use of performance indicators in performance analysis. Journal of Sports Sciences, 20, 739-754.

Hussein, A. (2009). The use of triangulation in social sciences research: Can qualitative and quantitative methods be combined? Journal of Comparative Social Research, 1, 1-12.

Kember, D., McKay, J., Sinclair, K., \& Wong, F.K.Y. (2008). A four-category scheme for coding and assessing the level of reflection in written work. Assessment and Evaluation in Higher Education, 33(4), 369-379.

Lai, K., \& White, T. (2012). Exploring quadrilaterals in a small group computing environment. Computers \& Education, 59, 963-973.

Lee, T.-H., Shen, P.-D., \& Tsai, C. W. (2008). Applying web-enabled problem-based learning and selfregulated learning to add value to computing education in Taiwan's vocational schools. Educational Technology \& Society, 11(3), 13-25.

Manolas, E., Kehagias, T. (2005). Kolb's experiential learning model: Enlivening physics courses in primary education. Proceedings of the 2nd International Conference, Hands-on Science: Science in a Changing Education, Rethymno, University of Crete, 286-289.

Mezirow, J. (1997). Transformative learning: Theory to practice. New Directions for Adult \& Continuing Education, 74, 5-12.

Nousiainen, M., Brydges, R., Backstein, D., \& Dubrowski, A. (2008). Comparison of expert instruction and computer-based video training in teaching fundamental surgical skills to medical students. Surgery, 143, 539-44.

Nurizan, A. W. (2009). The impact of peer teaching in improving students' motivation to learn science. Research@EastZone, 1, 106-124.

Olsen, W. (2004). Triangulation in social research, qualitative and quantitative methods can really be mixed. In M. Holborn (Ed.), Developments in Sociology: An Annual Review. Ormskirk, UK: Causeway Press.

Parikh, A., McReelis, K., \& Hodges, B. (2001). Student feedback in problem-based learning: a survey of 103 final year students across five Ontario medical schools. Medical Education, 35(7), 632-636.

Pintrich, P. R., Smith, D. A. F., García, T., \& McKeachie, W. J. (1991). A manual for the use of the motivated strategies for learning questionnaire (MSLQ). Ann Arbor: University of Michigan, National Center for Research to Improve Postsecondary Teaching and Learning.

Pintrich, P. R., Smith, D. A. F., García, T., \& McKeachie, W. J. (1993). Reliability and predictive validity of the motivated strategies for learning questionnaire (MSLQ). Educational and Psychological Measurement, 53, 801-813. 
Ryan, R. M., \& Deci, E. L. (2009). Promoting self-determined school engagement: Motivation, learning, and well-being. In K. R. Wentzel \& A. Wigfield (Eds.), Handbook of motivation at school (pp. 171196). New York: Routledge.

Shih, F.-J. (1998). Triangulation in nursing research: issues of conceptual clarity and purpose. Journal of Advanced Nursing, 28(3), 631-641.

Shyu, H. (2000). Using video-based anchored instruction to enhance learning: Taiwan's experience. British Journal of Educational Technology, 31, 57-6.

Strauss, A. (1987). Qualitative analysis for social scientists. New York: Cambridge University Press.

Tan, M., \& Saw Lan, O. (2011). Teaching mathematics and science in English in Malaysian classrooms: The impact of teacher beliefs on classroom practices and student learning. Journal of English for Academic Purposes, 10(1), 5-18.

Williams, J. J., \& Lombrozo, T. (2010). The role of explanation in discovery and generalization: evidence from category learning. Cognitive Science, 34, 776-806.

Wong, F. K., Kember, D., Chung L.Y., \& Yan, L. (1995). Assessing the level of student reflection from reflective journals. Journal of Advanced Nursing, 22(1), 48-57.

Yoo, M. S., Son, Y. S., Kim, Y. S., \& Park, J. H. (2009). Video-based self-assessment: Implementation and evaluation in an undergraduate nursing course. Nurse Education Today, 29, 585-589.

Yoo, M. S., Park, J. H., \& Lee, S. R. (2010). The effects of case-based learning using video on clinical decision making and learning motivation in undergraduate nursing students [Article in Korean]. Journal of the Korean Academy of Nursing, 40(6), 863-871.

Zahn, C., Pea, R., Hesse, F. W., Mills, M., Finke, M., \& Rosen, J. (2005). Advanced digital video technologies to support collaborative learning in school education and beyond. In T. Koschmann, D. Suthers, \& T.-W. Chan (Eds.), Computer Supported Collaborative Learning 2005: The Next 10 Years (pp. 737-742). Erlbaum.

Zimmerman, B. J. (1989). A social cognitive view of self-regulated academic learning. Journal of Educational Psychology, 81, 329-339.

Zimmerman, B. J., Bonner, S., \& Kovach, R. (1996). Developing self-regulated learners: Beyond achievement to self-efficacy. Washington, DC: American Psychological Association.

Corresponding author: Khalid Bin Abdul Jabbar, khalid_jabbar@rp.edu.sg

Australasian Journal of Educational Technology (C) 2013.

Please cite as: Bin Abdul Jabbar, K., Ong, A., Choy, J., \& Lim, L. (2013). Effects of experiential-based videos in multi-disciplinary learning. Australasian Journal of Educational Technology, 29(4), 526-536. 